\author{
Dr Danilo Ćuk, \\ dipl. inž., naučni savetnik \\ Vojnotehničkog instituta, \\ Beograd
}

\section{UTICAJ POVEĆANJA DOMETA NA DINAMIČKU STABILNOST ARTILJERIJSKIH RAKETA SA OLUČASTIM KRILIMA}

UDC: $623.463 .3:[533.6 .013 .4: 629.7 .01]$

Rezime:

U radu su prikazani efekti povećanja dometa artiljerijske rakete sa olučastim krilima na njenu dinamičku stabilnost. Totalni impuls raketnog motora, uvećan za 50\% i let rakete kroz slojeve atmosfere sa malom gustinom vazduha povećavaju domet rakete za više od $75 \%$ od nominalnog dometa. Međutim, let rakete kroz razređeni vazduh proizvodi teškoće koje se odnose na dinamičku stabilnost. Male promene bočnog momenta indukovanog napadnim uglom i Magnusovog momenta mogu proizvesti nestabilnost kretanja i nedozvoljeni rast napadnog ugla. Određene su tolerancije bočnog momenta za osnovnu i poboljšanu varijantu rakete radi sprečavanja nestabilnog leta. Analiziran je, takođe, uticaj povećanja dometa na verovatna odstupanja rakete po dometu i pravcu.

Ključne reči: nevođena raketa, putanja, dinamička stabilnost, rasturanje, olučasta krila.

\title{
INFLUENCE OF RANGE EXTENSION ON DYNAMIC STABILITY FOR ARTILLERY ROCKETS WITH WRAP AROUND FINS
}

\section{Summary:}

This paper presents the effects of the range extension of an artillery rocket with wrap around fins on its dynamic stability. The increased total impulse of the rocket engine for $50 \%$ and flight through the atmosphere layers with low air density extend the range for more than $75 \%$ of the nominal range. However, the flight of the unguided rocket through the rarefied air produces difficulties related to the dynamic stability. The small changes in the side moment which is induced by the angle of attack and Magnus moment of the improved rocket can produce instabilities in flight and increasement the angle of attack. The tolerances of the side moment were determined for both basic and improved type of the rocket in order to prevent instable flight. The influence of the range extension on the probable errors in range and cross-range was analyzed as well.

Key words: unguided rocket, trajectory, dynamic stability, dispersion, wrap around fins.

\section{Uvod}

Jedna od bitnih karakteristika razvoja savremenih višecevnih bacača raketa jeste primena raketa povećanog dometa, uz zadržavanje približno iste konfiguracije, sa mogućnošću lansiranja iz postojećih cevi. U zavisnosti od zahtevanog dometa, maksimalna brzina na kraju rada raketnog motora postiže se dovoljnim impulsom, uz minimalno povećanje mase rakete. Time dolazi do značajne promene Mahovog broja, koji neposredno utiče na aerodinamičke derivative stabilnosti kretanja, a time i na tačnost i preciznost ispaljenih raketa. Takav pristup u modernizaciji postojećih neupravljivih raketa zahteva analizu 
i proveru stabilnosti kretanja i određivanje tolerancija konstrukcionih parametara rakete, koji obezbeđuju dovoljnu stabilnost i minimalno rasturanje. Artiljerijske rakete obično imaju stabilizatore sa olučastim krilima koja su postavljena pod uglom u odnosu na uzdužnu osu, čime se generiše ugaona brzina valjanja radi smanjenja rasturanja zbog masene i aerodinamičke asimetrije konfiguracije i ekscentriciteta reaktivne sile. Pored toga, raketa mora da ima rotaciju neposredno po napuštanju lansirne cevi, što se postiže vođenjem rakete po zavojnom žlebu sa određenim korakom zavojnice. Domen promene ugaone brzine rotacije oko uzdužne ose rakete određen je uslovima koji ne dozvoljavaju da dođe do Magnusove nestabilnosti pri njenoj maksimalnoj vrednosti na kraju rada raketnog motora i rezonance pri njenoj minimalnoj vrednosti kada je najbliža učestanosti nutacionog kretanja [1], [2]. Određivanje tolerancije ugla ugradnje krila veoma je važan zadatak koji treba rešiti kod modifikovane rakete, posebno ako se imaju u vidu aerodinamičke osobine olučastih krila koje se menjaju u zavisnosti od režima leta: subsoničnog ili supersoničnog opstrujavanja.

Većina artiljerijskih raketa koristi olučasta krila zbog pogodnosti smeštaja oko cilindričnog tela pri lansiranju iz cevi. Međutim, aerodinamička konfiguracija rakete ima centralnu simetriju koja se karakteriše pojavom momenta valjanja pri nultim vrednostima napadnog ugla $i$ ugla ugradnje krila. Isto tako, pri napadnom uglu javlja se bočni moment koji je sličan Magnusovom momentu, ali ne za- visi od ugaone brzine valjanja. Njegov uticaj na stabilnost kretanja analiziran je u radovima [3] i [4], pri čemu je uzrok nestabilnog i neregularnog leta pripisan bočnom momentu indukovanom napadnim uglom, uz zanemarivanje Magnusovog momenta.

Cilj ovoga rada jeste uporedna analiza stabilnosti kretanja artiljerijskih raketa različitog dometa i ocena tolerancija ugla ugradnje olučastih krila i bočnog momenta, koji će obezbediti zahtevanu tehničku stabilnost ugaonog kretanja. $\mathrm{Na}$ kraju, performanse dve varijante rakete (nominalnog i povećanog dometa) biće prikazane preko verovatnih odstupanja po dometu i pravcu za iste ulazne slučajne veličine. Numerička simulacija leta rakete izvršena je na osnovu modela „6 stepeni slobode kretanja“ za neupravljivu raketu [5], [2], pri čemu je vršen simultani proračun svih parametara stabilnosti po metodi iz [1].

\section{Aerodinamička konfiguracija i osnovne karakteristike leta}

Posmatra se raketa sa olučastim krilima ukupne vitkosti tela $1 / \mathrm{d}=20-25$ (sl. 1). Zavisnost dometa od ugla lansiranja prikazana je na sl. 2. Raketni motor osnovne varijante (X-20) ima totalni impuls od $\sim 4000 \mathrm{dNs}$ i obezbezbeđuje maksimalni domet od $X=20,3 \mathrm{~km}$, pri uglu elevacije $\gamma_{0}=48^{\circ}$. Poboljšana verzija (X-35) ima nešto veću masu (do 5\% u odnosu na osnovnu varijantu), a pogonska grupa sa totalnim impulsom od 6000 dNs omogućava postizanje maksimalnog dometa od $\mathrm{X}=36,5 \mathrm{~km}$, pri uglu lansiranja $\gamma_{0}=54^{\circ}$. 


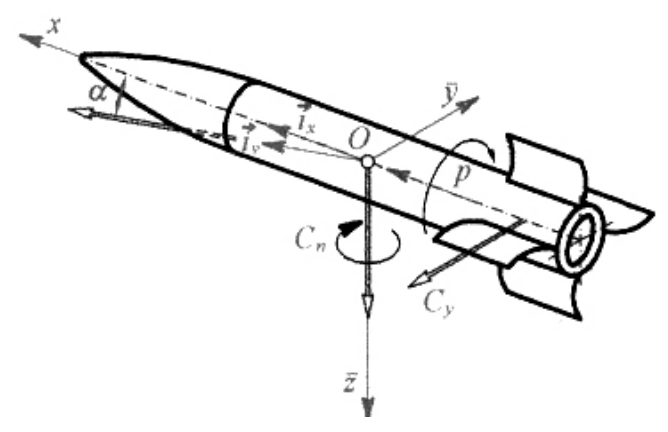

Sl. 1 - Aerodinamička konfiguracija

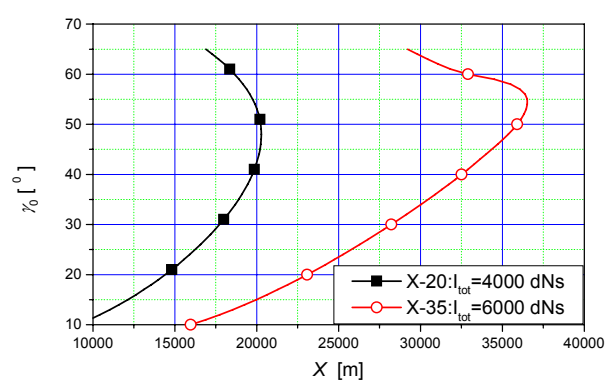

Sl. 2 - Zone lansiranja rakete

Povećanje totalnog impulsa od 50\% proširuje zonu lansiranja za više od $75 \%$, što modifikaciju čini privlačnom, uz postizanje stabilnosti i disperzije na zadovoljavajućem nivou. Sa sl. 2 odmah se uočava da je osetljivost maksimalnog dometa na promenu ugla elevacije znatno manji kod osnovne (X-20), nego kod poboljšane varijante (X35). Zato se može očekivati da će X-35 imati veće rasturanje na cilju od onog koje je srazmerno dometu kod obe varijante. Uporedni prikaz trajektorija, brzina i ugaonih brzina valjanja, koji približno odgovaraju maksimalnim daljinama gađanja obe varijante dat je na sl. 3, 4 i 5 respektivno. Dijagrami na sl. 3 ukazuju na to da je povećanje dometa od oko $80 \%$ rezultat ne samo uvećanog impulsa, već i kretanja rakete X-35 kroz veoma razređene slojeve atmosfere ko- ja utiče na znatno smanjenje otpora. Ovaj efekat praktično se gubi posle $\mathrm{t}=60 \mathrm{~s}$ (sl. 4). Mahov broj za osnovnu varijantu je manji od 2, dok je za poboljšanu raketu do 3,1. Da bi se ocenio uticaj olučastih krila na stabilnost kretanja, za raketu X-35 treba poznavati aerodinamičke karakteristike u proširenom dijapazonu Mahovih brojeva.

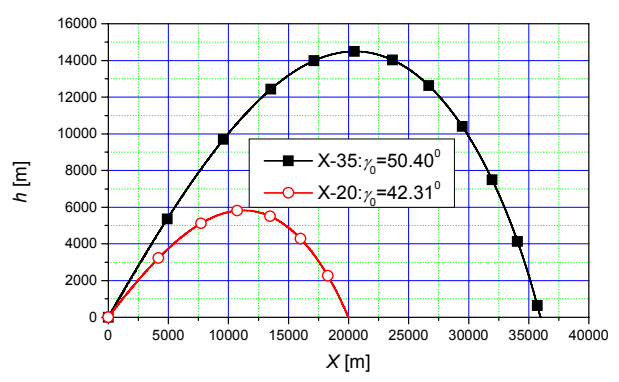

Sl. 3 - Trajektorije rakete

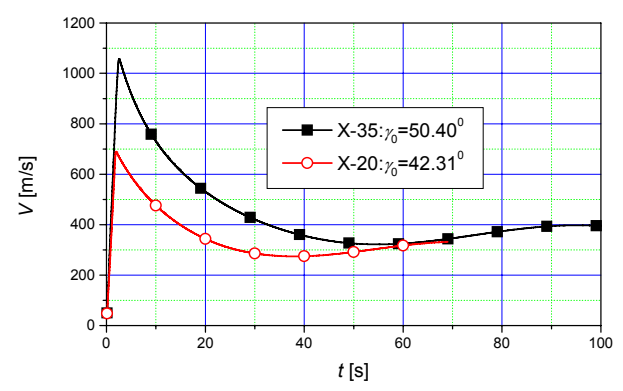

Sl. 4 - Brzina rakete

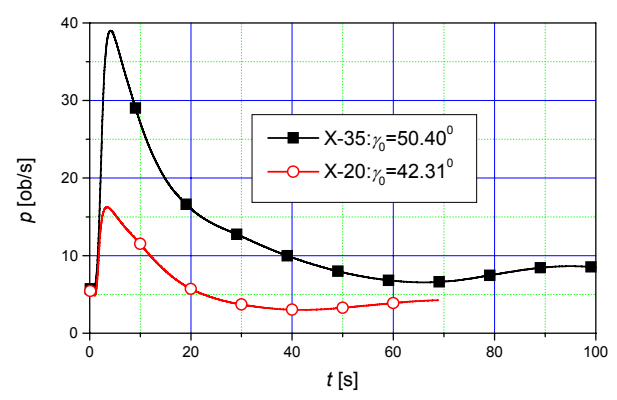

Sl. 5 - Ugaona brzina valjanja 
Ugaona brzina rotacije oko uzdužne ose ima približno istu vrednost od oko 5 obrtaja/s za obe varijante rakete $\mathrm{u}$ trenutku napuštanja lansirne cevi, što je posledica istog ugla zavojnice žleba. Osnovna varijanta X-20 dostiže ugaonu brzinu valjanja od 16 obrtaja/s po završetku rada raketnog motora, da bi u toku pasivne faze leta opala na minimalnu vrednost od oko 3 obrta$\mathrm{ja} / \mathrm{s}$. Maksimalna vrednost ugaone brzine valjanja za X-35 je nešto manja od 40 obrtaja/s, dok je njena minimalna vrednost oko 6 obrtaja/s. Kod obe varijante minimalna vrednost ugaone brzine valjanja je iznad nutacione učestanosti, tako da ne postoji mogućnost rezonance usled aerodinamičke ili masene asimetrije rakete. Velika vrednost ugaone brzine valjanja rakete u prvih nekoliko sekundi po prestanku rada raketnog motora ukazuje na neophodnost provere dinamičke stabilnosti $u$ zavisnosti od vrednosti Magnusovog momenta i disperzije ugaone brzine valjanja.

Aerodinamika olučastih krila detaljno je izučavana primenom savremenih numeričkih metoda ili ispitivanjem $u$ aerotunelu pri različitim Mahovim brojevima [6], [7], [8] i [9]. Aerodinamički moment valjanja nastaje usled diferencijalnog otklona konzola stabilizatora u odnosu na uzdužnu osu rakete i asimetrije opstrujavanja koja je izazvana oblikom olučastih krila i javlja se i pri nultim vrednostima napadnog ugla $(\alpha)$ i ugla ugradnje krila $\left(\delta_{1}\right)$. Šema komponenata koeficijenta momenta valjanja prikazana je na sl. 6 .
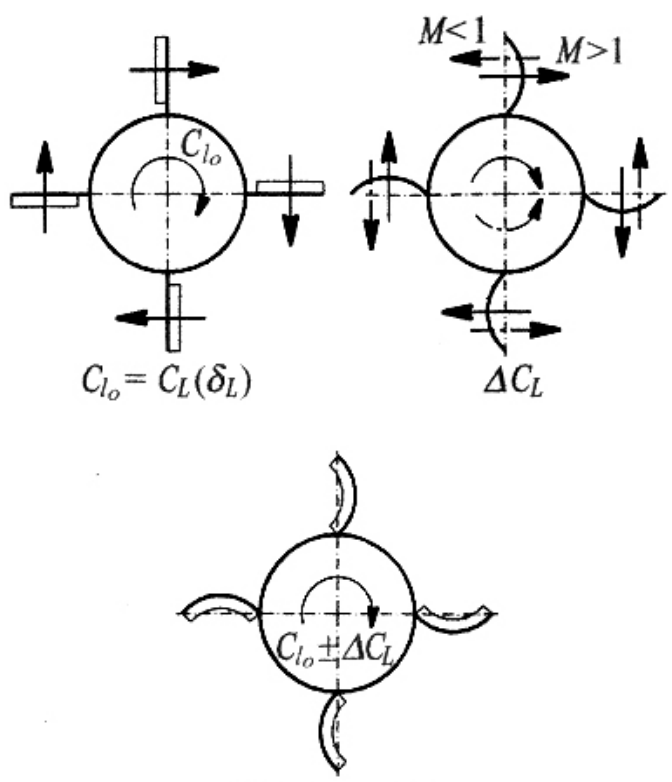

$$
\Delta C_{L}=C_{l_{o}} \pm \Delta C_{L}
$$

Sl. 6 - Koeficijent momenta valjanja M- Mahov broj

Imajući u vidu konačnu debljinu profila olučastih krila, površina konkavne strane biće uvek nešto manja od površine konveksne strane. U nadzvučnoj oblasti pritisak na konkavnoj strani je nešto veći od pritiska neporemećene struje (vazduh je komprimovan), dok je na konveksnoj strani pritisak nešto manji od referentne vrednosti (ekspandovan vazduh). Razlika u pritiscima generiše silu u smeru od konkavne prema konveksnoj strani, odnosno u smeru kretanja kazaljke na časovniku, posmatrano u pravcu leta (sl. 6), tako da se ova komponenta dodaje osnovnoj vrednosti usled diferencijalnog otklona konzola stabilizatora. Suprotno tome, u dozvučnoj oblasti pritisak na konkavnoj strani je manji od pritiska na konveksnoj strani, što rezultira u dodatnu komponentu negativnog znaka, koja smanjuje ukupnu vrednost momenta valjanja. Koeficijent dodatnog mo- 
menta valjanja zbog asimetrije olučastih krila prikazan je na sl. 7 [10], a njegov uticaj na ugaonu brzinu valjanja predstavljen je dijagramima na sl. 8. U supersoničnoj oblasti ovaj moment valjanja potpomaže rotaciju, tako da je ugaona brzina valjanja na kraju rada raketnog motora za $\sim 10$ obrtaja/s veća u odnosu na vrednost koja bi se dobila kod konfiguracije sa ravnim krilima. $\mathrm{U}$ transoničnoj oblasti moment valjanja zbog asimetrije krila menja znak, pa je ugaona brzina valjanja manja za oko 3 obrtaja/s u odnosu na vrednost koja odgovara ravnim krilima. Efekat asimetrije olučastih krila procenjuje se na $\sim \pm 0,2^{\circ}$ ekvivalentnog otklona ravnih krila, pri čemu znak vrednosti zavisi od režima opstrujavanja.

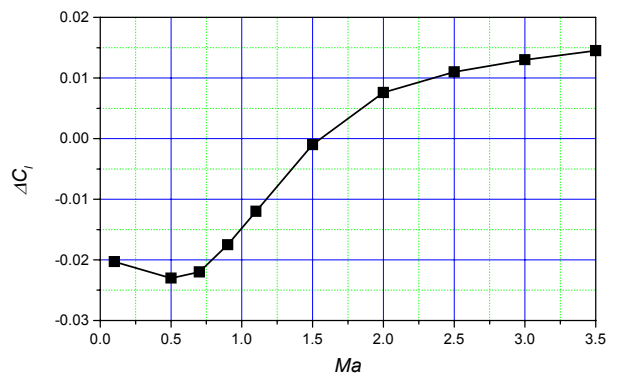

Sl. 7 - Moment valjanja zbog asimetrije olučastih krila [10]

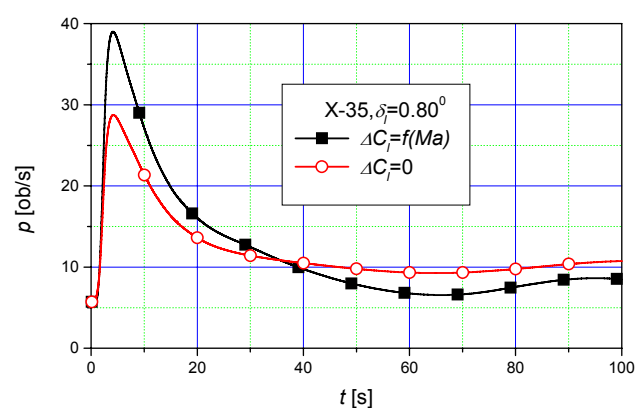

Sl. 8 - Uticaj asimetrije olučastih krila na ugaonu brzinu valjanja
Druga specifičnost olučastih krila jeste pojava bočne sile i momenta pri postojanju napadnog ugla i nultoj vrednosti ugaone brzine valjanja. Numerička simulacija strujnog polja i aerodinamička ispitivanja [6], [7], [3] pokazala su da za konfiguraciju na sl. 1 nastaje bočna sila nalevo, posmatrano u pravcu leta i bočni moment koji je usmeren u pozitivnom smeru ose Oz. Obuhvatajući i Magnusov efekat zbog rotacije rakete, ukupni bočni moment može se predstaviti izrazom:

$N=\frac{1}{2} \rho V^{2} S d\left(C_{n_{\alpha}}+C_{n_{p \alpha}} \frac{p d}{V}\right) i_{x} \times\left(i_{v} \times i_{x}\right)$

gde su:

$i_{x}-$ jedinični vektor uzdužne ose projektila;

$\mathrm{i}_{\mathrm{v}}-$ jedinični vektor brzine;

$\mathrm{C}_{\mathrm{n}_{\alpha}}$ - derivativ bočnog momenta;

$\mathrm{C}_{\mathrm{n}_{\mathrm{pu}}}$ - derivativ Magnusovog momenta.

Koeficijent bočnog momenta je:

$C_{n}=\left(C_{n_{\alpha}}+C_{n_{p \alpha}} \frac{p d}{V}\right) \sin \alpha_{T}$

gde je: $\alpha_{T}-$ totalni napadni ugao rakete.

U zavisnosti od vitkosti konfiguracije, a na osnovu aerodinamičkih eksperimentalnih i numeričkih rezultata o bočnom momentu [7], [3], procenjuju se vrednosti derivativa bočnog momenta po napadnom uglu:

$C_{n_{\alpha}}=-(0,06-0,12) C_{m_{\alpha}}$

Za aerodinamičku konfiguraciju rakete koja ima vitkost $1 / \mathrm{d}=20-25$ usvoje- 
na je sledeća nominalna vrednost za derivativ bočnog momenta:

$$
C_{n_{\alpha}}=-0,06 C_{m_{\alpha}}
$$

$\mathrm{Na}$ osnovu rezultata aerodinamičkog ispitivanja sličnih konfiguracija [11] procenjuje se aerodinamički derivativ Magnusovog momenta kao:

$$
C_{n_{p \alpha}}=-0,06 C_{m_{q}}
$$

gde je $\mathrm{C}_{\mathrm{m}_{\mathrm{q}}}$ aerodinamički derivativ prigušnog momenta propinjanja.

Vrednosti (4) i (5) mogu se koristiti za preliminarno aerodinamičko projektovanje i ocenu stabilnosti rakete. Definitivne vrednosti ovih aerodinamičkih derivativa moraju se utvrditi preciznim merenjem sila i momenata $u$ aerotunelu, koja će obuhvatiti uticaje svih važnih parametara olučastih krila: ugla ugradnje u odnosu na telo rakete, ugla otvaranja krila, geometrije prednjih i izlaznih ivica krila, veze krila i tela rakete, oblika profila, površine konzole, itd.

\section{Dinamička stabilnost rakete}

Stabilnost ugaonog kretanja raketnog projektila izučava se metodom koja je opisana $u$ radu [1] i predstavlja generalizaciju kriterijuma stabilnosti iz [12]. Za razliku od rada [12] u kojem se određuje stabilnost kompleksnog napadnog ugla, $\mathrm{u}$ [1] je izvedena diferencijalna jednačina kompleksne poprečne brzine rakete $\mathrm{u}$ aerobalističkom (nerotirajućem) koordinatnom sistemu:

$$
\tilde{\varsigma}^{\prime \prime}+(H-i P) \tilde{\varsigma}^{\prime}-(M+i P T) \tilde{\varsigma}=i A+i E+G
$$

gde su:

$$
\begin{aligned}
& H=C_{N_{\alpha}}^{*}-\left(C_{m_{q}}^{*}+C_{m_{\dot{\alpha}}}^{*}\right) \bar{r}_{y}^{-2} \\
& T=C_{N_{\alpha}}^{*}+\left(C_{n_{\alpha}}^{*} / p^{*}+C_{n_{p \alpha}}^{*}\right) \bar{r}_{x}^{-2} \\
& M=\left[\left(C_{m_{\alpha}}^{*}-C_{m_{\dot{\alpha}}}^{*} \frac{V^{\prime}}{V}\right)+C_{N_{\alpha}}^{*} C_{m_{q}}^{*}\right] \bar{r}_{y}^{-2} \\
& A=V\left(C_{m_{0}}^{*}+i C_{n_{0}}^{*}\right) \bar{r}_{y}^{-2} \\
& G=-\frac{d}{V}\left(g_{\tilde{y}}+i g_{\tilde{z}}\right)\left[\frac{V^{\prime}}{V}+\left(i P+C_{m_{q}}^{*} \bar{r}^{-2}\right)\right]
\end{aligned}
$$

$$
E=\frac{\tilde{M}^{F}+i \tilde{N}^{F}}{m V} \bar{r}_{y}^{-2}-i\left[\frac{d}{m V}\left(F_{\tilde{y}}+i F_{\tilde{z}}\right)\right]^{\prime}
$$

$P=\frac{J_{x}}{J_{y}} \frac{p d}{V}$

$$
p^{*}=\frac{p d}{V}
$$

$\overline{r_{x}}=\sqrt{\frac{J_{x}}{m d^{2}}}$

$\overline{r_{y}}=\sqrt{\frac{J_{y}}{m d^{2}}}$

$$
C^{*}=C \frac{\rho S d}{2 m}
$$

Veličina i predstavlja kompleksnu jedinicu $i=\sqrt{-1}$. Uvođenjem kompleksne poprečne brzine i bezdimenzionog puta, kao nezavisnopromenljive veličine, dobija se homogeni deo diferencijalne jednačine čiji su koeficijenti sporopromenljive funkcije bezdimenzionog puta, što omogućava primenu ,metode zamrzavanja koeficijenata" i nalaženje korenova karakteristične jednačine [1]:

$$
r_{j}=\lambda_{j} \pm \phi_{j}^{\prime}
$$


$\lambda_{j}=-\frac{1}{2}\left[H \pm \frac{P(2 T-H)}{\phi_{1}^{\prime}-\phi_{2}^{\prime}}\right]$

$$
\phi_{j}^{\prime}=\frac{1}{2}\left[P \pm \sqrt{P^{2}-4 M}\right], \mathrm{j}=1,2
$$

Tehnička stabilnost poprečne brzine raketnog projektila određena je uslovom:

$$
\lambda_{j}<\lambda
$$

gde je $\lambda$ najveća dopuštena vrednost prigušenja koja određuje maksimalnu vrednost amplitude poprečne brzine na određenom intervalu.

Primenom izraza (18) - (20) određuje se stabilnost poprečne brzine raketnog projektila bez obzira na fazu leta, kako u fazi ubrzavanja, tako i u pasivnoj fazi kad nema reaktivne sile. $\mathrm{Na}$ osnovu korenova karakteristične jednačine po poprečnoj brzini mogu se odrediti prigušenja kompleksnog napadnog ugla [1]:

$$
\begin{aligned}
& \lambda_{j \alpha}=\lambda_{j}+\lambda_{V} \\
& \lambda_{V}=-\frac{V^{\prime}}{V}
\end{aligned}
$$

$U$ fazi ubrzavanja $\lambda_{V}<0$, što znači da tangentno ubrzanje stabiliše napadni ugao. U pasivnoj fazi leta, pri usponu rakete, njeno gravitaciono ubrzanje i otpor destabilišu joj ugaono kretanje oko centra mase. Ako definišemo komponente prigušenja napadnog ugla koje zavise od derivativa prigušnog momenta i derivativa Magnusovog i bočnog momenta:

$$
\begin{aligned}
& \lambda\left(C_{m_{q}}\right)=-\frac{1}{2} H \\
& \lambda\left(C_{n_{\alpha}}\right)=\frac{1}{2} \frac{P(2 T-H)}{\phi_{1}^{\prime}-\phi_{2}^{\prime}}
\end{aligned}
$$

dobijamo sledeći oblik faktora prigušenja napadnog ugla:

$$
\lambda_{j \alpha}=\lambda\left(C_{m_{q}}\right) \pm \lambda\left(C_{n_{\alpha}}\right)+\lambda_{V}, j=1,2
$$

Znak ,,+" odnosi se na nutacioni oblik oscilovanja, a znak ,,“" na precesioni. $\mathrm{Za}$ aerodinamičke podatke koji su dati za konfiguraciju sa olučastim krilima, bočni i Magnusov moment destabilišu nutaciono kretanje, što znači da smanjuju apsolutnu vrednost faktora prigušenja $\lambda_{1 a}$. Zato je nutaciono kretanje rakete kritično, s obzirom na dinamičku stabilnost, pa će se u narednom odeljku analizirati promena $\lambda_{1 a}$ u zavisnosti od vremena leta rakete.

U radovima [3] i [4] dinamički faktor stabilnosti, koji je definisan u [12], zavisi od ugaone brzine valjanja, zbog čega se granična kriva domena stabilnosti ne dostiže po ordinati, kao u slučaju kada nema bočnog momenta, već po paraboli, kada ugaona brzina valjanja raste. Analiza dinamičke stabilnosti rakete sa olučastim krilima u ovom radu izvršena je na osnovu metode iz [1], jer je dovoljno opšta da je primenjiva na proizvoljni segment putanje.

\section{Analiza rezultata numeričke simulacije leta i dinamičke stabilnosti rakete}

U obe varijante rakete, $\mathrm{X}-20$ i X-35, ugaona brzina valjanja je izvan oblasti rezonance, uprkos negativnom efektu momenta valjanja od asimetrije olučastih krila, koji u transonečnoj oblasti menja znak i usporava rotaciju rakete oko uzdužne ose do minimalne vrednosti (sl. 8). 
Uporedni prikaz faktora prigušenja nutacionog oblika oscilovanja sa pojedinim komponentama iz izraza (26) dat je na sl. 9. Konfiguracija rakete X-35 je dinamički nestabilna u intervalu od 20 do $80 \mathrm{~s}$, što je posledica delovanja Magnusovog (5) i bočnog momenta (4).

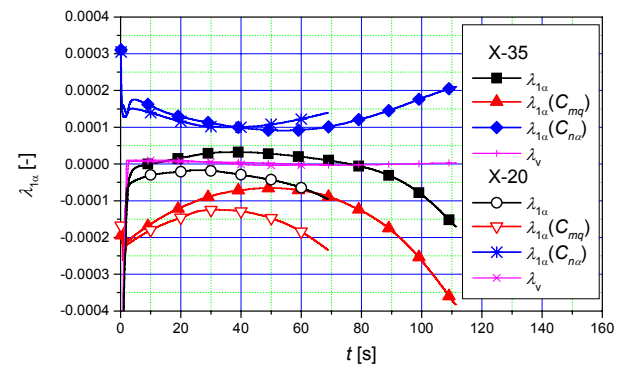

Sl. 9 - Prigušenje nutacionog kretanja

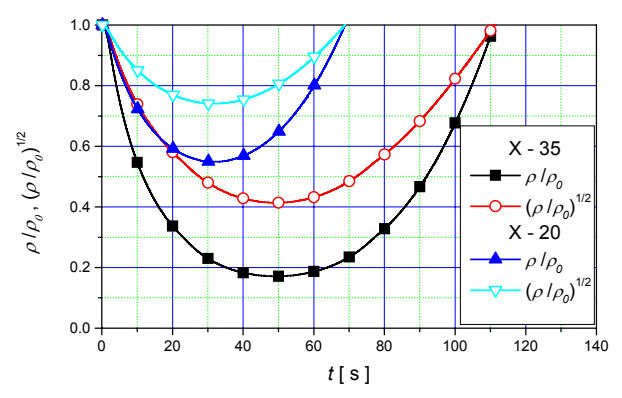

Sl. 10 - Promena gustine vazduha

Analizom pojedinih komponenata $\mathrm{u}$ faktoru prigušenja (26), koje su predstavljene dijagramima na sl. 9, pokazuje se da je član $\lambda_{1 \alpha}\left(\mathrm{C}_{\mathrm{m}_{\mathrm{q}}}\right)$ srazmeran gustini vazduha $\rho$, a član $\lambda_{1 \alpha}\left(C_{n_{\alpha}}\right)$ srazmeran kvadratnom korenu gustine vazduha $\sqrt{\rho}$. Zbog toga prvi član u faktoru prigušenja, $\lambda_{1 \alpha}\left(\mathrm{C}_{\mathrm{m}_{\mathrm{q}}}\right)$, ima karakter promene $\rho / \rho_{0}$, a drugi član odgovara funkciji $\sqrt{\rho / \rho_{0}}$. Ove funkcije prikazane su na sl. 10 , pri čemu $\rho_{0}$ predstavlja gustinu vazduha u početnom trenutku. Pošto $\lambda_{1 \alpha}\left(\mathrm{C}_{\mathrm{m}_{\mathrm{q}}}\right)$ brže opada po apsolutnoj vrednosti od $\lambda_{1 \alpha}\left(C_{n_{\alpha}}\right), u$ jednom trenutku $(\mathrm{t} \sim 20 \mathrm{~s})$ bočni i Magnusov moment postaju dominantni nad prigušnim momentom i nutaciono kretanje varijante $\mathrm{X}-35$ postaje nestabilno $\mathrm{u}$ intervalu $\mathrm{t} \in(20,80)$. Povratkom rakete $\mathrm{u}$ gušće slojeve atmosfere $(\mathrm{t}>80 \mathrm{~s})$ član $\lambda_{1 \alpha}\left(\mathrm{C}_{\mathrm{m}_{\mathrm{q}}}\right)$ postaje dominantan nad $\lambda_{1 \alpha}\left(\mathrm{C}_{\mathrm{n}_{\alpha}}\right)$ i ugaono kretanje rakete se vraća u stabilan režim (sl. 9). Za razliku od poboljšane varijante X-35, kod koje je pad gustine vazduha $\mathrm{u}$ temenu putanje veći od $80 \%$ (sl. 10), kod osnovne varijante X-20 ovaj pad gustine iznosi $45 \%$ od početne vrednosti, zbog čega se ne javlja dinamička nestabilnost. Dakle, povoljna okolnost kretanja rakete kroz razređene slojeve atmosfere, koja obezbeđuje znatno povećanje dometa, praćena je mogućnošću pojave dinamičke nestabilnosti. Zato je u slučaju varijante $\mathrm{X}-35$ veoma važno proceniti tačne vrednosti bočnog i Magnusovog momenta, odnosno izvršiti korekcije aerodinamičke konfiguracije radi smanjenja ovih aerodinamičkih poremećaja.

Uticaj promene bočnog momenta pri konstantnom Magnusovom momentu na faktor prigušenja $\lambda_{1 \alpha}$ prikazan je na sl. 11 za osnovnu varijantu X-20, a na sl. 12 za poboljšanu varijantu. Numeričkom simulacijom leta rakete pomoću modela „6 stepeni slobode kretanja“ dobijeni su di- 
jagrami rezultujućeg napadnog ugla, sl. 13 i sl. 14, koji su u potpunosti konzistentni sa teorijom dinamičke stabilnosti i dijagramima na sl. 11 i sl. 12.

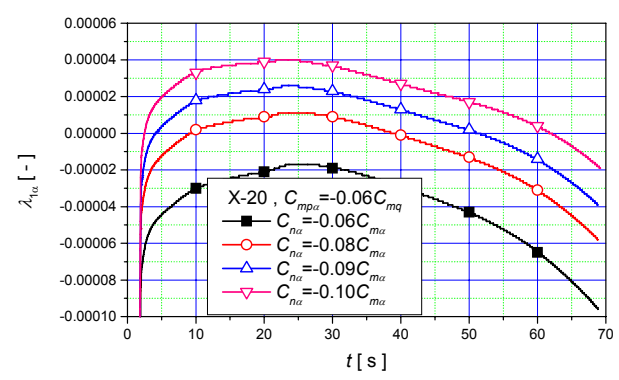

Sl. 11 - Uticaj bočnog momenta na prigušenje nutacionog kretanja za X-20

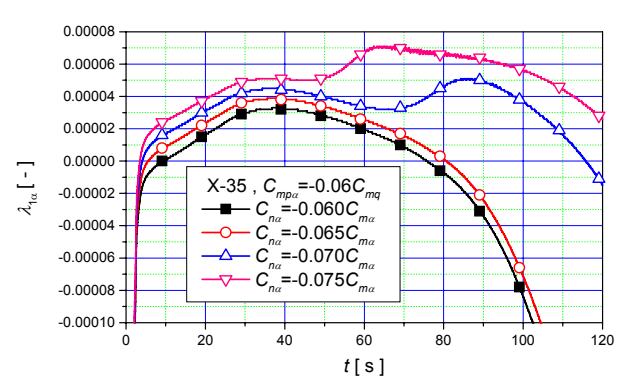

Sl. 12 - Uticaj bočnog momenta na prigušenje nutacionog kretanja za $X$-35

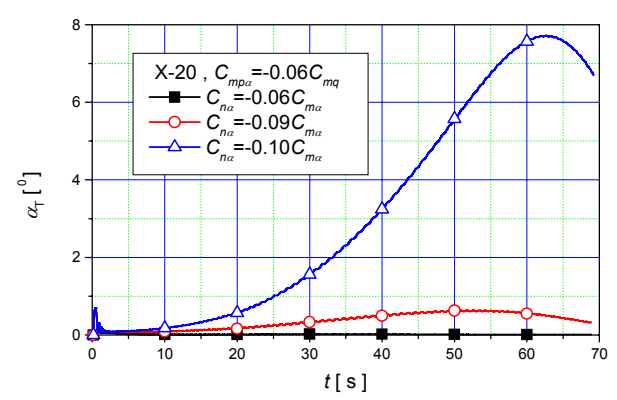

Sl. 13 - Uticaj bočnog momenta na napadni ugao za $X-20$

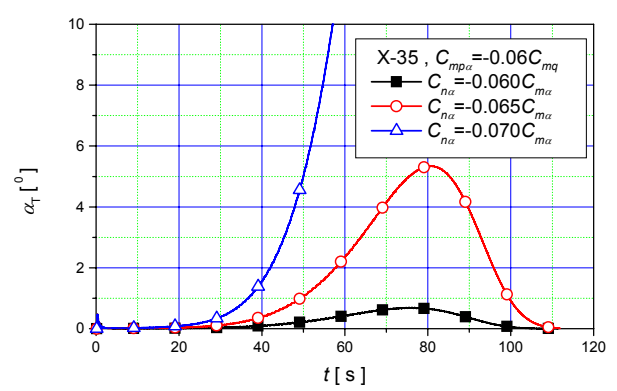

Sl. 14 - Uticaj bočnog momenta na napadni ugao za X-35

Male promene $u$ bočnom momentu mogu dovesti do dinamičke nestabilnosti varijante X-35 i velikih vrednosti napadnog ugla. Bez obzira na to što u nekim slučajevima raketa može da savlada ovu promenu napadnog ugla i da se vrati $u$ stabilan režim leta, radi smanjenja disperzije rakete geometrijske karakteristike olučastih krila treba optimizirati tako da generišu minimalni bočni moment. Suprotno tome, raketa X-20 je dovoljno robustna na veće promene bočnog momenta, tako da ne dolazi do velikog porasta napadnog ugla.

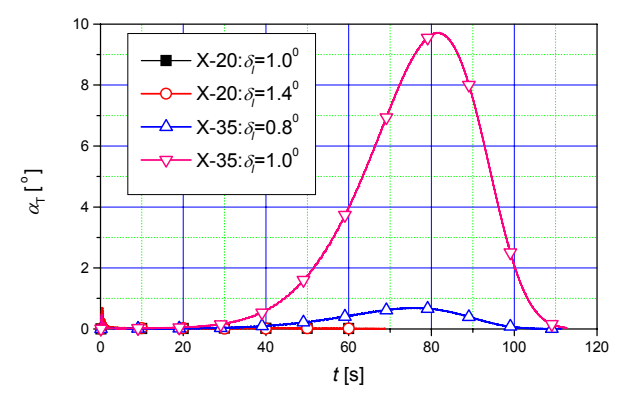

Sl. 15 - Uticaj ugla ugradnje krila na napadni ugao

Efekat promene ugla ugradnje olučastih krila na napadni ugao i ugaonu brzinu valjanja predstavljen je dijagramima na sl. 15 i 16, respektivno. Promena ugla 
ugradnje krila od $0,2^{\circ}$ može da izazove dinamičku nestabilnost i neželjeni porast napadnog ugla kod X-35 (sl. 15). Suprotno tome, kod varijante X-20 promena ugla ugradnje od $0,4^{\circ}$ nema nikakvog uticaja na promenu napadnog ugla.

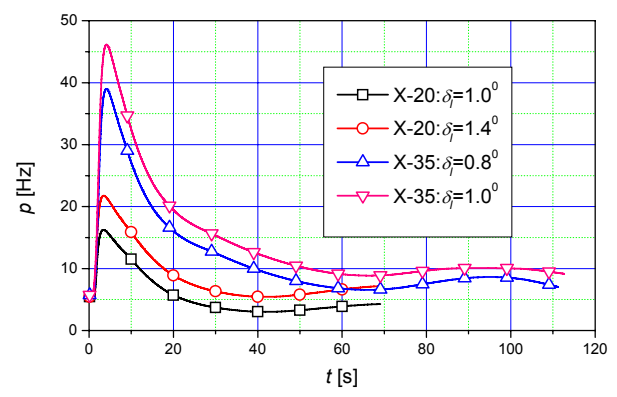

Sl. 16 - Uticaj ugla ugradnje krila na ugaonu brzinu valjanja

\section{Disperzija rakete na cilju}

Primenom matematičkog modela ,6 stepeni slobode kretanja“ i metode Monte Karlo izvršena je ocena statističkih parametara padnih tačaka obe varijante rakete $\mathrm{u}$ mirnoj atmosferi za parametre čije su statističke karakteristike prikazane u tabeli. Uticaj oruđa obuhvaćen je samo preko početnih poremećaja napadnog ugla $\alpha_{0} \mathrm{i}$ ugla klizanja $\beta_{0}$, kao i komponenata ugaone brzine projektila $\mathrm{p}_{0}, \mathrm{q}_{0}, \mathrm{r}_{0}$. Sve veličine u tabeli, sem mase, imaju normalni zakon raspodele sa datom standardnom devijacijom $\sigma_{\mathrm{i}}$. Disperzija početne mase podleže uniformnoj raspodeli sa intervalom $\Delta \mathrm{m}$. Položaj ravni odstupanja sile potiska $\left(\varepsilon_{\mathrm{F}}\right)$ i male aerodinamičke asimetrije $\left(\alpha_{n}\right)$ takođe podležu uniformnoj raspodeli sa intervalom $(0,2 \pi)$. Za svaki zadati domet određeni su uglovi lansiranja, pa je izvršen proračun 31 putanje. Nakon statističke obrade dobijena su verovatna odstupanja po dometu $\left(\mathrm{V}_{\mathrm{d}}\right)$ i pravcu $\left(\mathrm{V}_{\mathrm{p}}\right)$, za obe varijante rakete (sl. 17). U slučaju varijante $X-20$ verovatno odstupanje po pravcu monotono raste, a verovatno odstupanje po dometu monotono opada sa daljinom cilja. Elipsa rasturanja, sa dužom osom u pravcu gađanja, pri manjim daljinama gađanja prelazi u elipsu rasturanja sa dužom osom upravno na pravac gađanja na maksimalnim dometima rakete. Varijanta rakete X35 odstupa od ove teorijske zavisnosti slike rasturanja od daljine cilja $i$ verovatno odstupanje po dometu $\mathrm{V}_{\mathrm{d}}$ raste, kao i $\mathrm{V}_{\mathrm{p}}$, za domete $X>28 \mathrm{~km}$. Veće vrednosti verovatnog odstupanja po dometu kod varijante X-35 posledica je veće osetljivosti dinamičke stabilnosti na promenu slučajnih konstrukcionih parametara, pre svega ugla ugradnje krila stabilizatora $\left(\delta_{1}\right)$, kako je to pokazano na sl. 15 i sl. 16.

Tabela

Statistika ulaznih veličina

\begin{tabular}{|c|c|c|c|}
\hline Veličina & $\sigma_{\mathrm{i}}$ & Veličina & $\sigma_{\mathrm{i}}$ \\
\hline $\mathrm{F}$ & $1 \%$ & $\alpha_{0}, \beta_{0}$ & $0,1^{\circ}$ \\
\hline$\varepsilon_{\mathrm{F}}$ & $2 \mathrm{mrad}$ & $\mathrm{p}_{0}$ & $1 \mathrm{rad} / \mathrm{s}$ \\
\hline$\delta_{1}$ & $0,07^{\circ}$ & $\mathrm{q}_{0}, \mathrm{r}_{0}$ & $0,1 \mathrm{rad} / \mathrm{s}$ \\
\hline$\Delta \mathrm{m}$ & $0,200 \mathrm{~kg}$ & $\alpha_{\mathrm{n}}$ & $0,05^{\circ}$ \\
\hline
\end{tabular}

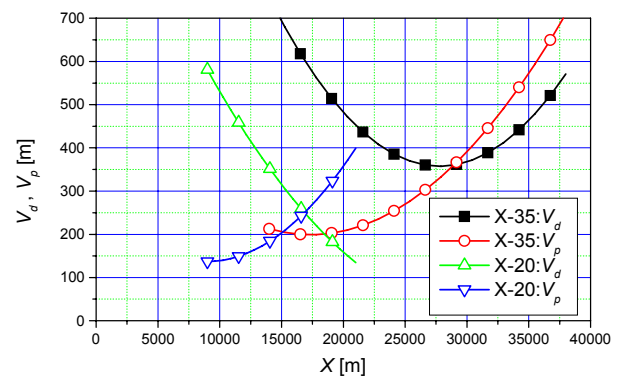

Sl. 17 - Verovatna odstupanja rakete 


\section{Zaključak}

$\mathrm{U}$ radu su istaknute aerodinamičke specifičnosti artiljerijske rakete sa olučastim krilima, a zatim je analiziran njihov uticaj na dinamičku stabilnost rakete $\mathrm{u}$ funkciji povećanja dometa. Povećanje totalnog impulsa raketnog motora i let rakete kroz razređene slojeve atmosfere omogućili su znatno povećanje dometa. Međutim, smanjena gustina vazduha (i do $80 \%$ u temenu putanje rakete $\mathrm{X}-35$ ) povećava osetljivost dinamičke stabilnosti na promenu bočnog i Magnusovog momenta ili na ugao ugradnje krila stabilizatora. Bez obzira na to što raketa u nekim slučajevima može da savlada porast napadnog ugla, ovu pojavu treba sprečiti da bi se ograničila verovatna odstupanja rakete po dometu i pravcu. Zbog toga, tolerancija ugla ugradnje krila poboljšane varijante X-35 treba da bude znatno manja $\mathrm{u}$ poređenju sa istim parametrom osnovne varijante X-20.

$\mathrm{Na}$ osnovu empirijskih vrednosti bočnog momenta izvršena je analiza dinamičke stabilnosti rakete i pokazano je pri kojim vrednostima aerodinamičkog derivativa ovog momenta dolazi do neželjenog rasta napadnog ugla, što rezultira velikim otporom i povećanim rasturanjem rakete. Numeričkom simulacijom leta rakete pomoću modela „6 stepeni slobode kretanja“ i proračunom dinamičke stabilnosti rakete dobijeni su konzistentni rezultati koji objašnjavaju uzroke nestabilnog leta rakete X-35 i veliku robustnost osnovne varijante X-20 na disperziju konstrukcionih parametara. Ukazano je na potrebu preciznog merenja bočnog i Magnusovog momenta radi optimizacije olučastih krila minimizacijom odnosa bočnog momenta i momenta $u$ ravni rezultujućeg napadnog ugla.

\section{Spisak oznaka}

A - koeficijent u (6)

$\mathrm{C}_{\mathrm{N}_{\alpha}}$ - derivativ normalne sile po napadnom uglu, $\mathrm{C}_{\mathrm{N}_{\alpha}}=\partial \mathrm{C}_{\mathrm{N}} / \partial \alpha$

$\mathrm{C}_{\mathrm{m}_{\alpha}}$ - derivativ momenta propinjanja po napadnom uglu, $\mathrm{C}_{\mathrm{m}_{\alpha}}=\partial \mathrm{C}_{\mathrm{m}} / \partial \alpha$

$\mathrm{C}_{\mathrm{m}_{\mathrm{q}}}, \mathrm{C}_{\mathrm{m}_{\dot{\alpha}}}$ - derivativi prigušnog momenta

$\mathrm{C}_{\mathrm{m}_{0}}, \mathrm{C}_{\mathrm{n}_{0}}-$ aerodinamički koeficijenti momenta pri nultom napadnom uglu $\mathrm{C}_{\mathrm{n}}-$ aerodinamički koeficijent bočnog momenta

$\mathrm{C}_{\mathrm{n}_{\alpha}}$ - derivativ bočnog momenta po napadnom uglu

$\mathrm{C}_{\mathrm{n}_{\mathrm{p}}}$ - derivativ Magnusovog momenta

$\Delta \mathrm{C}_{1}-$ koeficijent momenta valjanja od asimetrije olučastih krila

$\mathrm{d}$ - referentna dužina rakete, $\mathrm{m}$

E - koeficijent u (6)

$\mathrm{F}-\operatorname{potisak}[\mathrm{N}]$

$\mathrm{F}_{\tilde{y}}, \mathrm{~F}_{\tilde{z}}-$ projekcije potiska na ose aeroba-

lističkog koordinatnog sistema, $\mathrm{N}$

$\mathrm{g}_{\tilde{y}}, \mathrm{~g}_{\tilde{z}}-$ projekcije gravitacionog ubrza-

nja na ose aerobalističkog sistema, $\mathrm{m} / \mathrm{s}^{2}$

$\mathrm{H}$ - koeficijent $\mathrm{u}(6)$

$\mathrm{J}_{\mathrm{x}}, \mathrm{J}_{\mathrm{y}}-$ uzdužni i poprečni moment iner-

cije rakete, $\mathrm{kgm}^{2}$

$\mathrm{M}$ - koeficijent u (6)

$\mathrm{m}$ - masa projektila, $\mathrm{kg}$

$\mathrm{N}$ - bočni moment, $\mathrm{N}$

$\tilde{\mathrm{M}}^{\mathrm{F}}, \tilde{\mathrm{N}}^{\mathrm{F}}$ - projekcije reaktivnog momenta na ose aerobalističkog sistema, $\mathrm{Nm}$

$\mathrm{P}$ - koeficijent u (6) 
$\mathrm{p}^{*}$ - bezdimenziona ugaona brzina valjanja, $\mathrm{p}^{*}=\mathrm{pd} / \mathrm{V}$

$\mathrm{p}, \tilde{\mathrm{q}}, \tilde{\mathrm{r}}$ - projekcije ugaone brzine projektila $\mathrm{u}$ aerobalističkom sistemu, $\mathrm{rad} / \mathrm{s}$ $\left(r_{j}, j=1,2\right)$ - koreni karakteristične jednačine za kompleksnu poprečnu brzinu $\overline{r_{x}}, \overline{r_{y}}-$ bezdimenzioni poluprečnici inercije rakete

$\mathrm{S}$ - referentna površina, $\mathrm{m}^{2}$

$\mathrm{s}^{*}-$ bezdimenzioni put, $\mathrm{s}^{*}=\mathrm{s} / \mathrm{d}$

$\mathrm{T}$ - koeficijent u (6)

$\mathrm{t}$ - vreme, $\mathrm{s}$

$\mathrm{V}$ - brzina projektila, $\mathrm{m} / \mathrm{s}$

$\mathrm{V}_{\mathrm{d}}$ - verovatno odstupanje po dometu, $\mathrm{m}$

$\mathrm{V}_{\mathrm{p}}$ - verovatno odstupanje po pravcu, $\mathrm{m}$

$\mathrm{X}$ - domet rakete, $\mathrm{m}, \mathrm{km}$

$\alpha, \tilde{\alpha}$ - napadni ugao $\mathrm{u}$ dinamičkom $\mathrm{i}$ aerobalističkom sistemu, rad, ${ }^{0}$

$\alpha_{n}-$ ugao aerodinamičke nesimetrije rakete, $\mathrm{rad}^{0}{ }^{0}$

$\beta, \tilde{\beta}$ - ugao klizanja u dinamičkom i aerobalističkom sistemu, $\mathrm{rad}^{0}$ $\alpha_{\mathrm{T}}-$ rezultujući napadni ugao, $\mathrm{rad}^{0}{ }^{0}$

$\gamma$ - ugao nagiba putanje, $\mathrm{rad}^{0}{ }^{0}$

$\delta_{1}$ - ugao ugradnje krila stabilizatora, $\mathrm{rad}^{0}{ }^{0}$

$\varepsilon_{\mathrm{F}}-$ ekscentricitet reaktivne sile, $\mathrm{mrad}$

$\left(\lambda_{\mathrm{j}}, \mathrm{j}=1,2\right)$ - prigušenje nutacije i prece-

sije po poprečnoj brzini

$\left(\lambda_{j \alpha}, j=1,2\right)$ - prigušenje nutacije i pre-

cesije po napadnom uglu

$\lambda\left(\mathrm{C}_{\mathrm{m}_{\mathrm{q}}}\right)$ - prigušenje definisano sa (24)

$\lambda\left(\mathrm{C}_{\mathrm{n}_{\alpha}}\right)$ - prigušenje definisano sa (25)

$\lambda_{\mathrm{V}}-$ prigušenje definisano sa (23)

$\lambda$ - dozvoljena vrednost prigušenja $\rho$ - gustina vazduha, $\mathrm{kg} / \mathrm{m}^{3}$

$\left(\phi_{\mathrm{j}}^{\prime}, \mathrm{j}=1,2\right)$ - bezdimenziona učestanost nutacije i precesije

$\tilde{\varsigma}$ - kompleksna poprečna brzina, $\mathrm{m} / \mathrm{s}$

$\sigma_{i}-$ standardna devijacija i-te veličine

( ) - izvod po bezdimenzionom putu s*

$\sim-$ aerobalistički koordinatni sistem Oxỹz̃

0 - početna vrednost neke veličine

$(\mathrm{C})^{*}-\mathrm{C} \times \frac{\rho \mathrm{Sd}}{2 \mathrm{~m}}$

$\times$ - vektorski proizvod

Literatura:

[1] Ćuk, D.; Ćurčin, M.: Stabilnost nekih parametara kretanja neupravljivih raketnih projektila, Naučno-tehnički pregled, Vol. XXXVII, 1987, br. 8.

[2] Janković, S.; Ćuk, D.: Mehanika leta projektila, Predavanja iz mehanike leta projektila na Mašinskom fakultetu u Beogradu i Tehničkoj vojnoj akademiji u Zagrebu, 1988.

[3] Morote, J., Liano G.: Stability Analysis and Flight Trials of a Clipped Wrap Around Fin Configuration, AIAA Atmospheric Flight Mechanics Conference and Exibit, 16-19 August 2004, Providence, Rhode Island.

[4] Morote, J., Liano G.: Roll Rate Stability Limits of Unguided Rockets with Wrap Around Fins, $43^{\text {rd }}$ AIAA Aerospace Science Meeting and Exibit, 10-13 January 2005, Reno, Nevada.

[5] Ćuk, D.: Program UNCPTC6D - Program za proračun kretanja neupravljivog projektila primenom modela „6 stepen slobode kretanja“ i simultano određivanje dinamičke stabilnosti, Beograd, 2007.

[6] Abate, G. L.; Winchenbach G.: Analysis of Wrap Around Fin and Alternative Deployable Fin Systems for Missiles, Meetings on ,Subsystem Integration for Tactical Missiles (SITM) and Design and Operation of Unmanned Air Vehicles (DOUAV)“, Ankara, 9-12 October 1995.

[7] Berner, C.; Abate, G.; Dupuis, A.: Aerodynamics of Wrap Around Fins using Experimental and Computational Techniques, Simposium on „Missile Aerodynamics“, Sorrento, Italy 11-14 May 1998.

[8] Tilmann, C. P.; McIntyre, T. C.: Aerodynamics of Wrap Around Fins at High Supersonic Speeds, Simposium on „Missile Aerodynamics“, Sorrento, Italy 11-14 May 1998.

[9] Swenson, M. W.; Abate, G. L.; White R. H.: Aerodynamic Test and Analysis of Wrap Around Fins at Supersonic Mach Numbers Utilizing Design of Experiments, $28^{\text {th }}$ Aerospace Science Meeting\&Exibit, Reno, Nevada 10-13 January 1994.

[10] Mandić, S.; Analysis of the Rolling Moment Coefficient of the Rocket with Wrap Around Fins, Scientific-Technical Review, Vol. LVI, No. 2, 2006.

[11] Nicolaides, J. D.; Ingram, C. W.; Tarkowski, D. D.: Nonlinear Aerodynamic Characteristics of Sounding Rockets, J. Spacecraft, Vol. 8, No. 11, 1971.

[12] Murphy, C. H.; Symmetric Missile Dynamic Instabilities, J. Guidance and Control, Vol. 4, No. 5, pp. 464-471, 1981. 